Military Technical College
Kobry El-Kobbah,
Cairo, Egypt

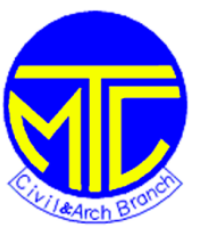

$10^{\text {th }}$ International Conference on Civil and Architecture Engineering ICCAE-10-2014

\title{
Experimental Investigation of the Performance of Alluvium Soil Reinforced With Jute Cloth
}

\author{
Wassim R. Azzam ${ }^{1}$ and Nabil M. Nagy ${ }^{2}$ \\ ${ }^{1}$ Assoc. Prof. Structural Engineering Department, Faculty of Engineering, Tanta University, Tanta, Egypt \\ ${ }^{2}$ Assoc. Prof. Civil Eng. Department, Military Technical Collage - Cairo, EGYPT.
}

\begin{abstract}
Soil reinforcement is a recent and special field of soil improvement. It covers a range of techniques, which consists of placing inclusions in soil. The most conferences devoted partly or totally the behavior of foundation on reinforced subgrade without regarding the basic characteristics of the reinforced soil. So, the paper presents an experimental investigation into the mechanical and compressibility properties of the reinforced silty clay samples by jute cloth at intermediate depth. The effects of the reinforcement on shear stress and shear failure were studied, also, the presence the reinforcement on behavior of consolidation process was distinctly described. The laboratory tests were supported by the finite element analysis to identify only the consolidation process and explained the effect of the reinforcement on the effective vertical stress and pore water pressure. The results indicted that the presence of such reinforcement has a considerable effect in increasing the shear strength of the reinforced samples and decreasing the compressibility especially decreasing the soil movement also, relief both the effective and pore water pressure.
\end{abstract}

Key words: Soil reinforcement, Jute cloth, Shear stress, Shear parameters, Compressibility, Silty clay and Settlement.

\section{Introduction}

Civil engineers around the world are in search of new alternative materials which are required both for cost effective solutions for ground improvement and for conservation of scarce natural resources. The various methods of ground improvement currently in use include lime columns, stone columns, use of chemical stabilizers and various kinds of inclusions like metal strips, mats, fibres, geosynthetics, etc. The cost of these virgin materials as well as the processes involved are usually high and as such they are yet to be commonly used in developing foundation performances. On the other hand good quality conventional natural resources like sand, gravel, aggregates etc are fast depleting with the increase in construction activities in the country and there is a ban on new quarries, due to environmental concerns. As such there is a growing need of a material which can partially replace the soil and providing improved properties. The techniques of soil reinforcement were done by including new materials into the soil in various forms. Applications of reinforcement in civil engineering have been successfully developed and offer benefits in terms of economics, durability and performance. It play important role in geotechnical engineering works, especially highway and railroad, reinforced soil, stabilisation of soil or rock slopes, drainage control, embankment, dames, and tunnel.

The use of soil reinforcement materials are effective means of stabilization poor soils whereas they are used worldwide in many areas of civil engineering works. Much work has been carried out during the past decades on the behavior of the reinforced earth retaining wall e.g. Vidal, (1969) and Lee et al., (1975). The application of soil reinforcement for improving the bearing capacity and the load settlement response of the foundations, the base for pavements and embankments on soft soil were studied. Binquet and Lee, (1975), proved that the presence of tensile reinforcing strips under footing increases and improves the bearing capacity of supporting soil and decreases the stress over weak layer. Abdrabbo, (1979, 1993), Giroud, (1981) and Mahmoud, (1988), Abdel-Baki et al., (1993, 1994), Mandal and Manjunath, (1994), studied the method of improving the bearing capacity of footing model resting on sand subgrades reinforced by a variety of reinforcement. While Leshchinsky et al., (1989) and Hirao et al., (1997) study the application of the composite fabrics on soft ground and reinforced soil structure without determination of the mechanical or any characteristics of reinforced soil. For extent, Watn et al., (1997) 
and Saleh, (2002) explained the improvement of the bearing capacity of strip footing by using geosynthtic reinforcement placed in horizontal manner. Al-kaisi et al., (2004) investigated the suitability of using some natural material as reinforcement for sand. Haripal et al., 2008 and Patra et al., 2010 also, studied the technique of soil reinforcement placed below the foundation to improve the bearing capacity of the footing soil system.

The last mentioned papers describe the results of the loading tests on a variety of horizontal reinforced layers beneath the footing. It deals with the study the effect of the existence of reinforcement on the bearing capacity of any footing without considering the effect of the existence such reinforcement on the geotechnical properties of the tested soil. In addition, all the paper in literature were directly concerned with the use of sandy or cohesionless soil in their investigation with the exception of using another soil. It also used a common material of soil reinforcement neglecting available waste materials. So, the present paper tries to discover and analyze the use of available cheaper waste materials, jute cloth as an extensible reinforcement. This investigation aims to study and evaluate both the mechanical and compressibility characteristics of reinforced alluvium soil located in central delta of Egypt by the adopted such waste material. Recently there has been a strong demand for the use of both the mechanical and compressibility properties of cohesive soil, which reinforced by different reinforcement techniques. Because these properties are most important in foundations uses. Also, it was used in a wide range in computer programs. A jute cloth is locally available in industrial waste products, economy and easy to obtain all over the world. The subsequent study involved soil characterization and reinforcement material evaluations to determine appropriate parameters for design and construction control for reinforced samples.

\section{Site under investigation and sampling}

The tested samples were taken from the alluvium soil in central delta of Egypt. The percentage of silt in soil samples ranged between $69 \%$ to $75 \%$. The sample is classified as CL according to unified soil classification.

\section{Testing program}

A complete laboratory program is performed on each sample as follow:

1. Hydrometer analysis. The grain size distribution curve for the tested samples are shown in figure 1 . The sample is classified as silty clay with trace of sand ( $8 \%$ sand : $70 \%$ silt : $22 \%$ clay)

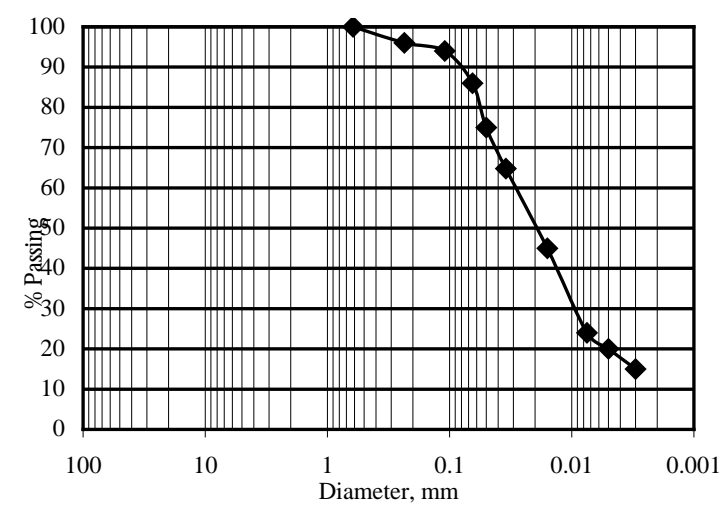

Fig.1: Grain size distribution curve from hydrometer test for the tested sample.

2. Atterberg limits, which mean the determination of the water content, liquid limit, plastic limit and plasticity index. The consistency values were determined according to ASTM specification respectively as follows: 33\%, 37\%, 15\% and 22. The initial void ratio was found to be 0.9248 at bulk density $18.5 \mathrm{kN} / \mathrm{m}^{2}$ and specific gravity $(\mathrm{Gs}=2.68)$.

3. Direct shear tests for both unreinforced and reinforced samples to study the effect of the existence of the reinforcement on the shear parameters of the tested sample and induced shear stresses. The apparatus used in these tests is the shear box apparatus. The box is square $(6 \mathrm{~cm} \times 6 \mathrm{~cm})$ in section by $(2 \mathrm{~cm})$ thick and it is split horizontally at level of the center of the soil specimen, the lower half of the box is rigidly held in position in a container. Where, a series of direct shear tests at different normal stresses were carried out for both reinforced and unreinforced sample. The samples were reinforced by reinforced elements at the middle part between the two part of shear box (Figure 2a) at the plan of failure in direct shear to simulate the actual state in the field Mofiz et al., (2004). All tests were carried out at submerged state and at bulk density of $18.5 \mathrm{kN} / \mathrm{m}^{3}$. 


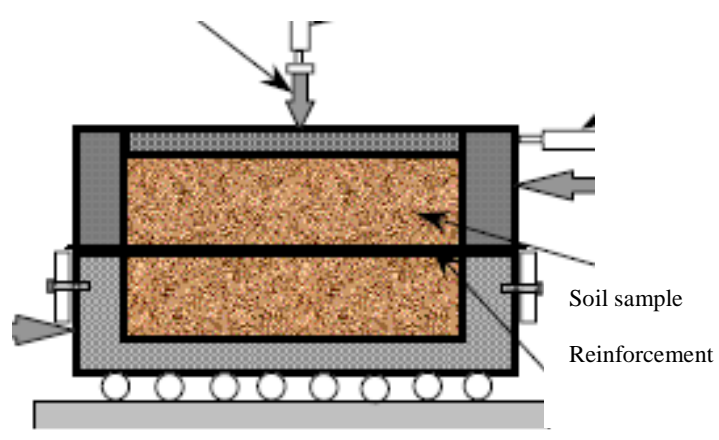

Fig. 2a: Direct shear box and placing of reinforcement material or jute clothe.

4. Consolidation tests for both unreinforced and reinforced samples to determine the basic compressibility characteristics. The convention Oedometer was used. It consists of a consolidation cell of diameter (110 mm), brass rings diameter (750 mm) and height $(19 \mathrm{~mm})$. Porous plate machine to fit into the ring, bottom porous plate of diameter (75 mm) and a loading cap. A series of the consolidation tests were carried out at submerged state for both reinforced and unreinforced samples, also the samples were reinforced by reinforced elements at the middle depth or on the halve of the odometer ring.

All the tests were run following immediately the placement and preparation of soil in the shear box and Oedometer which represent mainly the short-term conditions developed in the corresponding field application.

5. Reinforced element. The adopted reinforcement element is a woven type jute cloth as a waste material (Figure 2b). Its physical and strength properties were determined in the laboratory using standard methods of ASTM for geotextiles. The thickness, mass per unit area and breaking strength or failure strength were measured as $1.25 \mathrm{~mm}, 225 \mathrm{~g} / \mathrm{m}^{2}$ and $10.9 \mathrm{~N} / \mathrm{mm}$ respectively. The failure strength at elongation $14.5 \%$.

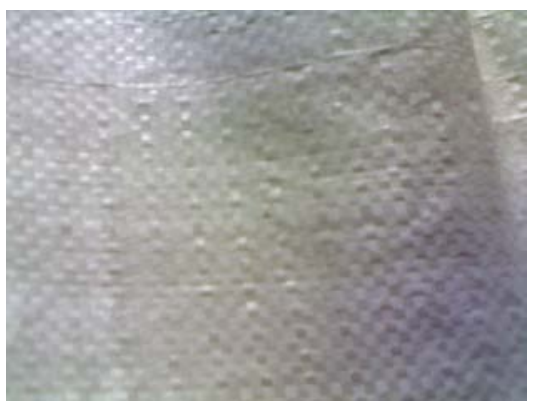

Fig. 2b: Reinforcement element or jute clothe adopted in the present investigation.

\section{Experimental results and discussion}

\section{Direct shear stress results}

\section{Shear stress versus shear displacement}

Figure 3 and 4 show the shear stress versus shear displacement curves at the three-stress level of normal stress for specimens with and without reinforcement. The same is true for the residual shear strength. It has been found that, the peak shear strength increases with normal stress for both reinforced and unreinforced samples. The increase in the shear strength leads to decrease in the shear displacement as illustrated in the last figures. The existence of the reinforcement at the interface in the direct shear was distinctly reduced the shear displacement because such reinforcement was induced additional shear strength. In addition, the shear modulus of the reinforced samples exhibits no change under various normal stress, but larger than that under zero normal stress and without reinforcement. As expected, the reinforced soil samples exhibit higher shear strength than unreinforced samples and the maximum shear strength were gradually attained at lower shear strains. The shear stress of unreinforced specimen was reduced after the post peak value. On the other hand for reinforced soil, strain-hardening behavior was observed due to conversion of brittle for the unreinforced soil to ductile behavior of the composite material. Moreover, the maximum shear displacement at peak shear strength for reinforced sample falls within a narrow range, with an increase in normal stress from $15 \mathrm{kN} / \mathrm{m}^{2}$ to $55 \mathrm{kN} / \mathrm{m}^{2}$ the shear displacement falls from $0.4 \mathrm{~cm}$ to $0.33 \mathrm{~cm}$. Generally, with a few exceptions, both the peak and residual shear strengths are larger for specimens with reinforcement than those without reinforcement. 


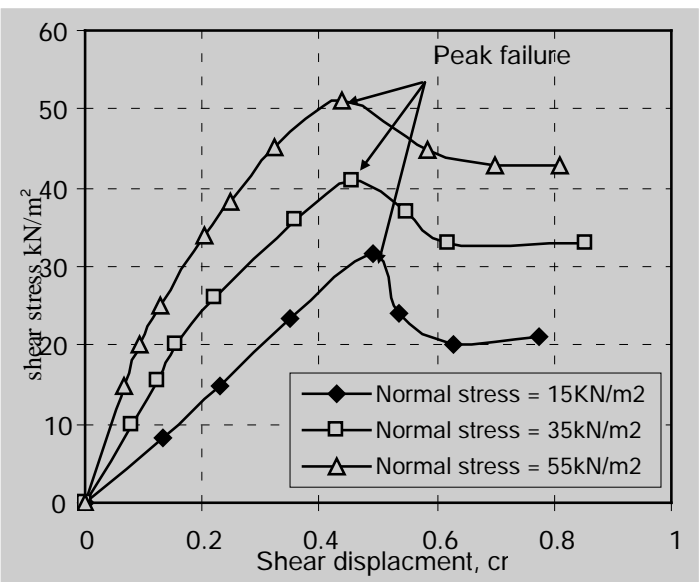

Fig. 3: Shear stress versus shear displacement curves at three levels of normal stress for unreinforced case.

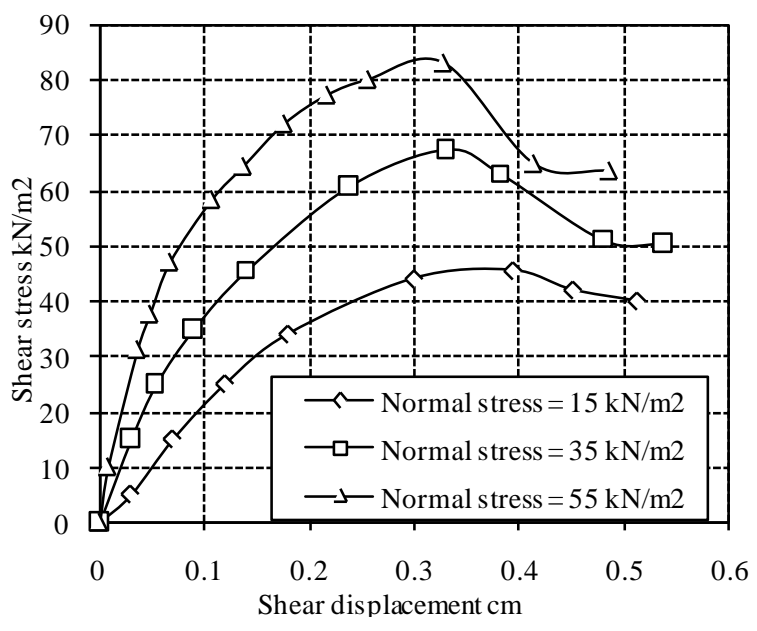

Fig. 4: Shear stress versus shear displacement curves at three levels of normal stress for reinforced case.

Basically, two types of failure were encountered, that are, peak failure and slippage failure. A peak failure was distinguished in the unreinforced soil by the sliding between the particles of the samples, which located between the upper and lower part in the direct shear. A slippage failure was distinguished by occurrence of splitting or rips off between the reinforcement material and the soil. The slippage failure related to applied normal stress, type of soil and interface friction of the reinforcement.

\subsubsection{Shear stress versus vertical displacement}

From the test results it is also observed that the vertical displacement vs. shear displacement behavior revealed that expansion is more pronounced especially at lower normal stress. The results of unreinforced and reinforced soil samples also show that dilatancy is dependent on the normal stress and the existence of such reinforcement (Figure 5). The result shows different strain pattern at higher displacement when the soil samples started to dilate. In all tests, before occurrence of failure, yielding is considered, where the vertical displacement was very insignificant or slightly increased. But thereafter, it followed two pattern of behavior depending on the types of failure. As applied stress in the specimens reached its yield point, the vertical displacement began to increase and continued to increase until peak failure occurred. This is clarified and confirmed by the Figure 5 which show the relationship between the shear stress and the vertical displacement at a given normal stress ( $\sigma$ $=35 \mathrm{kN} / \mathrm{m}^{2}$ ). It was expected that the existence of the layer of reinforcement decrease the vertical displacement, where the reinforcement prevent the soil particles from vertical movement i. e. reducing the settlement. Also, it has been found that, when the applied stress in unreinforced samples reached the peak failure strength, and the failure occurred the general trend of vertical displacement was decreased until the development of the residual stress then it became constant except for slight variations. While, in the reinforced sample the vertical displacement generally continued to increase until the test was completed because the soil not reached to failure. Also, the variation in the vertical displacement was decreased in unreinforced soil sample. The variation in the magnitude of vertical displacement was also affected by the magnitude of the normal stress, soil type and reinforcement material.

\subsubsection{Failure curves for reinforced and unreinforced soils}

Figure 6 show the shear stress versus normal stress curves for both reinforced and unreinforced samples. The linear regression was used to analyze the test data to study the effect of the reinforcement on the shear parameters of tested samples. It can be indicated that the failure curves can be adequately represented by a straight line. The slope of this line corresponds to the internal friction angle and its coordinate at the origin corresponds to the apparent cohesion. As shown in figure 6, the shear parameters results of the unreinforced sample were, angle of internal friction $\left(\phi=15^{\circ}\right)$ and cohesion $\left(\mathrm{C}=24 \mathrm{kN} / \mathrm{m}^{2}\right)$. On the other hand, the existence of the reinforcement was increased and improved the mechanical parameters of the tested sample where, the reinforcement had a considerable effect on the increasing the shear strength of soil due to frictional interaction between the soil and inclusions. In the other way, for the reinforced samples, it can be observed that the expected values of the angle of internal friction $\left(\phi=20^{\circ}\right)$ and cohesion ( $C=31 \mathrm{kN} / \mathrm{m}^{2}$ ). That is means the reinforcement had a distinctly effect on 
the mobilization of addition shear strength. It noticed that, the angle of internal friction was increased by (33\%) and the apparent cohesion also increased by (29\%) of its initial values. The failure equation can be reformulated as follows for each cases:

$$
\begin{array}{lc}
\tau=C+\sigma_{\mathrm{n}}(\tan \phi) & \text { (unreinf. samples) } \\
\tau=\alpha C+\sigma_{\mathrm{n}}(\tan \beta \phi) & \text { (reinf. samples) }
\end{array}
$$

Where, $\tau$ is the shear strength of the tested soil, $C$ is the initial cohesion of unreinforced sample, $f$ is the initial angle of internal friction of unreinforced sample and $\sigma_{\mathrm{n}}$ is the acting normal stress. $(\alpha, \beta)$ are the improvement factor due to reinforcement effect for cohesion and angle of shear resistance respectively, in the present case it has been found that ( $(\alpha=1.33$ and $\beta=1.29)$.Form the last mentioned equation it can be concluded that at the same normal stress the shear strength of the reinforced samples can be increased by $33 \%$ of its initial value of unreinforced case.

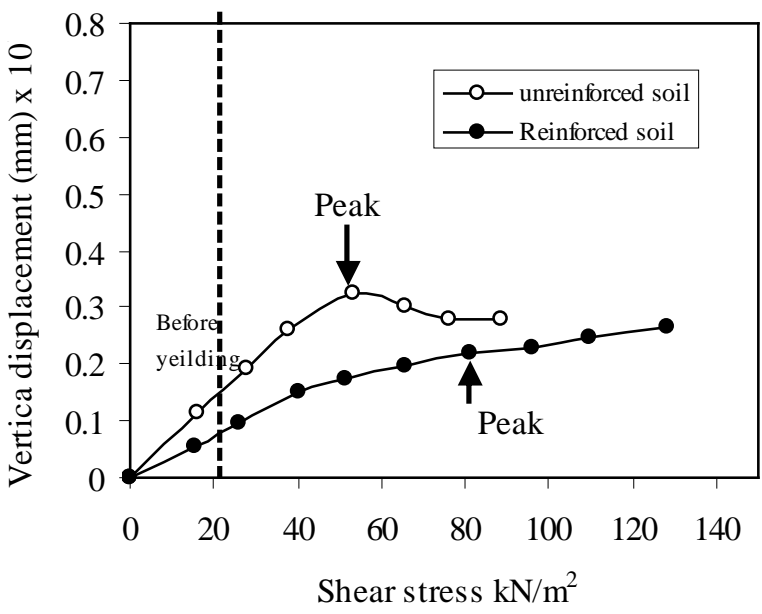

Fig.5: Shear stress versus vertical displacement at the normal stress $\sigma=35 \mathrm{kN} / \mathrm{m}^{2}$ for reinforced and unreinforced soil

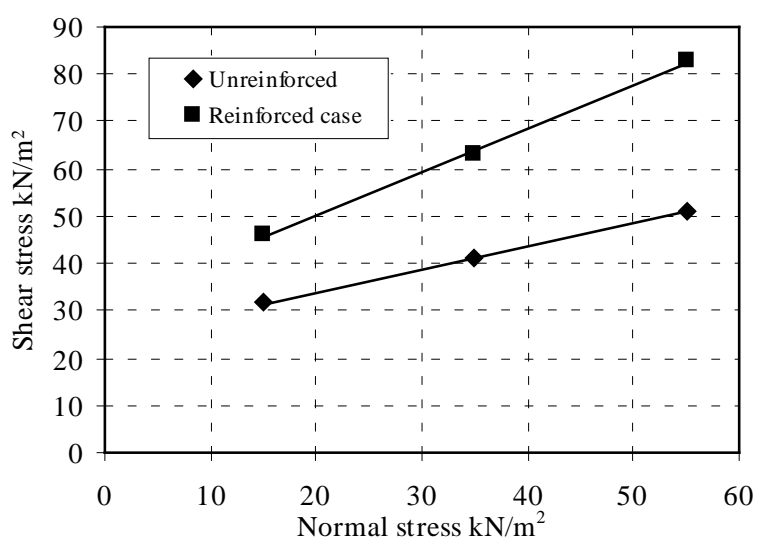

Fig. 6: Comparison failure envelope for reinforced and unreinforced soil.

\subsection{Consolidation test results}

\subsubsection{Variation of void ratio with the vertical stress}

The results of consolidation test are usually presented in the form of voids ratio versus logarithm of effective pressure. These results are presented through Figure 7 for both reinforced and unreinforced samples. It is clearly seen that the void ratio decreases as the vertical stress increases for two cases. That is backed to the pore water pressure dissipation. The existence of the reinforcement sharply decreases the expected volume change and vertical deformation hence, the corresponding void ratio was also decreased with the comparison of unreinforced sample. It has been found that at the pressure $100 \mathrm{kN} / \mathrm{m}^{2}$ the void ratio sharply decreased for each case because the reinforcement was decreased the settlement. Also, the compression index Cc of the reinforced samples less than of the unreinforced case that is referred to the inclusions decreases the compressibility of the tested soil. For extent, the value of the coefficient of compressibility $\mathrm{a}_{\mathrm{v}}$ for the unreinforced sample was found to be ( $\mathrm{a}_{\mathrm{v}}=$ 
$\left.0.00098 \mathrm{~m}^{2} / \mathrm{kN}\right)$ and the coefficient of volume change $\left(\mathrm{m}_{\mathrm{v}}=0.00049 \mathrm{~m}^{2} / \mathrm{kN}\right)$. And the modulus of elasticity of the ordinary samples $\left(E_{\text {unreinf. }}=2040 \mathrm{kN} / \mathrm{m}^{2}\right)$. But for the reinforced samples, it has been noticed that values of the compressibility factors $\left(a_{v}=6.65 \times 10^{-4} \mathrm{~m}^{2} / \mathrm{kN}\right.$ and $\left.\mathrm{m}_{\mathrm{v}}=0.00035 \mathrm{~m}^{2} / \mathrm{kN}\right)$ were decreased due to reinforcement effect. It was expected that the inclusions decreases the settlement and increase the compressibility of soil where the value of the modulus of elasticity of the reinforced samples was diverted to $\left(E_{\text {reinf. }}=2850 \mathrm{kN} / \mathrm{m}^{2}\right)$ i. e. the reinforcement was improved the compressibility of soil to sustain any deformation and reduced the stresses within the soil. It can be increase the ductility and performance of tested soil.

\section{Effect of the reinforcement on the drained properties}

In order to study the effect of the reinforcement on the coefficient of permeability of the tested sample. The relationship between the settlement and log time for both reinforced and unreinforced sample was plotted in figure 7. It noticed that the settlement of all samples increases with time and the existence of reinforcement decreasing the settlement. That is means the reinforcement decreasing the flow and drainage of water in samples. Otherwise, the coefficient of consolidation (Cv) can be obtained at degree of consolidation ( $\mathrm{U}=50 \%$ ). The extracted values of $\mathrm{Cv}$ for both unreinforced and reinforced sample were ( $3.675 \mathrm{~mm} / \mathrm{min}$ and $2.05 \mathrm{~mm} / \mathrm{min})$. And the corresponding coefficient of permeability were found $\left(\mathrm{K}=3 \mathrm{x} 10^{-8} \mathrm{~cm} / \mathrm{sec}\right.$ for unreinforced sample and $\mathrm{K}=1.35 \times 10^{-9} \mathrm{~cm} / \mathrm{sec}$ for reinforced sample). It concluded that the reinforcement played an

important role in controlling the flow of the water through the reinforced samples, it can be decreased the coefficient of permeability and delayed the consolidation process. These reasons were reflected on decreasing the resulting settlement

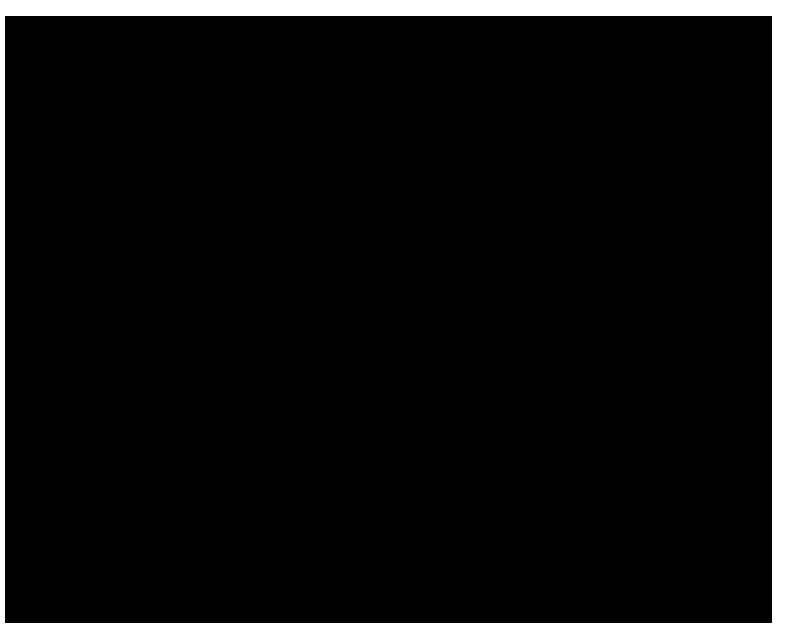

Fig. 7: The relationship between void ratio and pressure for reinforced and unreinforced soil sample

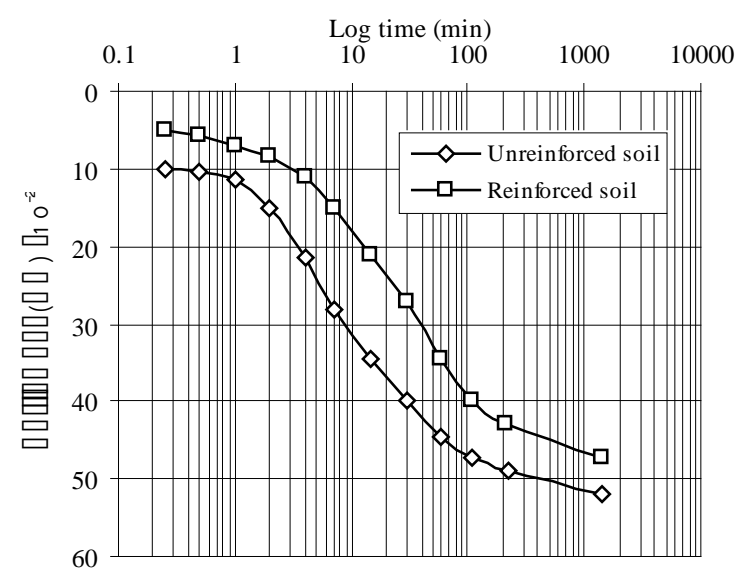

Fig. 8: Settlement - log time curve for reinforced and unreinforced soil.

\section{Finite element modeling}

In order to identify the behavior of the reinforced soil sample during the consolidation process. The numerical study using finite element method was carried out. The finite element can be particularly useful for identifying the pattern of deformation and effective stress distribution in the soil. In addition, describe the behavior of pore water pressure in the existence of such reinforcement technique. It also clarified the deformation and axial forces in the reinforcement during the consolidation process. The plain strain elastoplastic finite element analysis was carried out using the commercial program PLAXIS (Bringkgreve and Vermeer, 1998). All the finite element calculations were based on six-nodded triangular elements with a three-point Gaussian integration rule to calculate the element stiffness matrices. In this study, the soil modeled using an elastoplastic Mohr-Coulomb model. The basic parameters of Mohr-Coulomb model require a total of five parameters which are generally familiar to most geotechnical engineers and which can be obtained from basic tests on soil sample. 
The reinforced element was modeled in our investigation by using elastic geotextile elements, having zero bending stiffness. Geotextile only sustain tensile forces and no compression. Geotextile is composed of geotextile element when 6-node soil element are employed then each geotextile element is defined by 3-nodes. Whereas, 5-node geotextile are used in combination with 15-nodes soil elements. Axial forces are evaluated at the Newton-Cotes stress points. This type of stress points is also used for interface elements. The only material property of geotextile is an elastic normal stiffness EA where, E is the modulus of elasticity of the material used and A: cross section area.

For the problem of the one-dimensional consolidation, in the present investigation the soil model is simulated as the soil sample in oedeometr apparatus with similar diameter and thickness. The left and right vertical line of the model in figure 9 were constrained horizontally, and the bottom horizontal boundary was constrained in both directions. Closed consolidation boundary conditions is applied only in the left right and bottom of sample and upper drainage is allowed. An excess pore water pressure is generated by using untrained material behavior and applying an external load in the first calculation phase. The reinforced soil is reinforced by jute reinforcement at the middle depth.

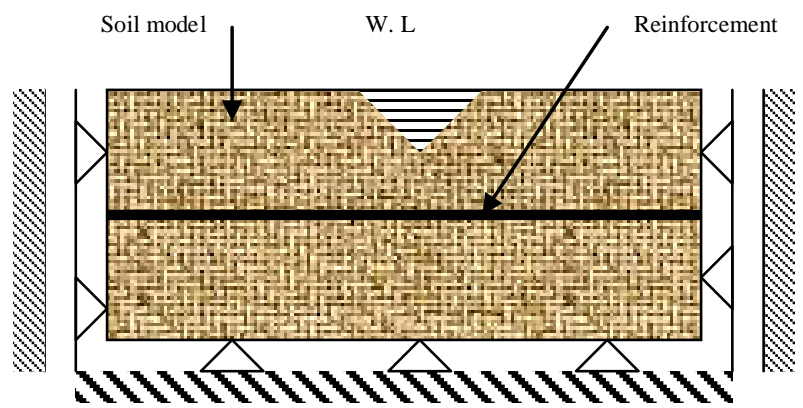

Fig. 9: Schematic diagram for the element of mathematical model of consolidation cell used in finite element analysis.

\section{Finite element results}

Results of the finite element analysis are shown in (Figures 10 - 15). Figure 10 shows the deformed mesh for the problem of one-dimensional consolidation for unreinforced sample. It characterized by large deformation and large settlement in the comparison with reinforced case.

The existence of the reinforcement decreasing the deformation and vertical deformations. Figure 11 and 12 show the distribution of the vertical effective stress and the development of the excess pore pressure along the soil length respectively for unreinforced soil. It has been found that, both vertical effective stress and pore water pressure increases gradually in the absent of reinforcement. It also noticed that the maximum increase from mid depth to the bottom of sample. However the reinforcement significantly decreasing the sample deformation (Figure 13) and modifying both the effective vertical stress and the pore water pressure in the upper halve of soil over the reinforced element. Because the induced shear strength at the interface of the reinforcement sustain the acting vertical stress and it can be transmitted to axial force resisted by the reinforcement. As presented in Figure 14 and 15, these figures show that both the vertical effective stress and pore water pressure, were redistributed and increasing gradually from the point at which the reinforced element was located. It noticed that the maximum forces in the reinforced element were found at each side of reinforcement where at the middle of element there were high confining pressure and low shear stress, so stress was increased at each side of reinforcement as presented in last figures.

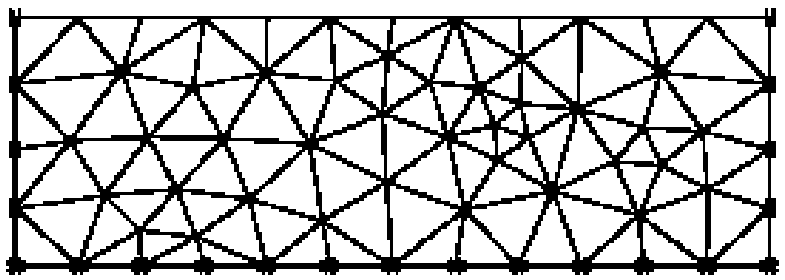

Fig. 10: The deformed mesh for unreinforced sample.

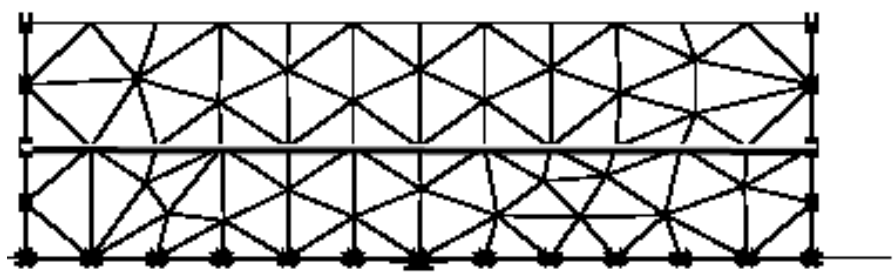

Fig. 13: The deformed mesh for reinforced sample.

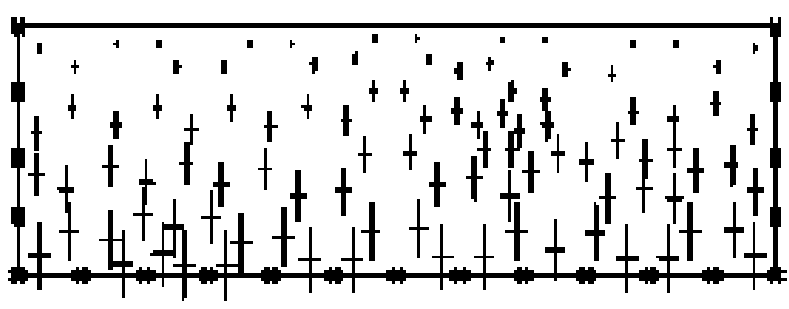

Fig. 11: The effective stress a long the sample depth for unreinforced

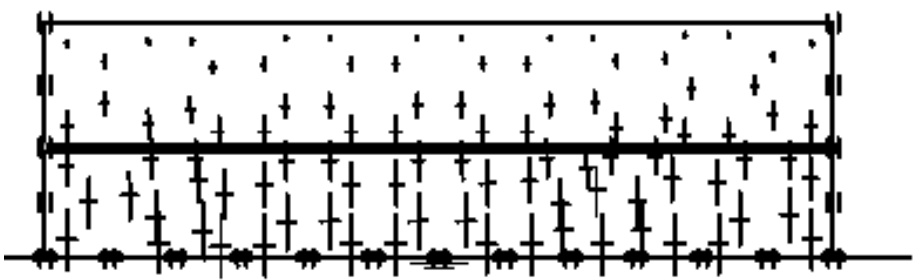

Fig. 14: The effective stress a long the sample depth for reinforced 


\section{Conclusions}

This work is aimed to more understanding of the basic fundamental characteristics of reinforced silty clay soil by jute cloth in lieu of soil reinforcement. The beneficial effect of the reinforcement in the mechanical and compressibility parameters were presented. The adopted waste material of this jut was considered as cheap and effective reinforcement element compared with other reinforced materials.

From these studies the following conclusions can be drawn:

1) The presence of the reinforcement at the interface in direct shear decreasing the shear displacement.

2) The shear modulus of the reinforced samples exhibits no change in shear displacement under various normal stresses.

3) The peak and residual shear strengths are larger for specimens with reinforcement than those without reinforcement.

4) The use of jute cloth as reinforced element has a great influence on the vertical soil movement. It has decreased effectively the vertical displacement.

5) The vertical displacement beyond the peak failure for unreinforced soil is decreased and increased for reinforced soil.

6) The presence of the reinforcement was made the vertical displacement generally continued to increase until the test was completed. Contrary for the unreinforced sample the vertical displacement generally continued to decrease until the test was completed.

7) The presence of the reinforcement was modified the failure pattern from peak failure to slippage failure

8) The reinforcement had a considerable effect on the increasing the angle of internal friction and the apparent cohesion.

9) The existence of such reinforcement increases the shear strength by $33 \%$ of its initial value of unreinforced case at the same normal stress.

10)Based on the consolidation tests, it has been found that the presence of the layer of reinforcement at the middle of sample was decreased the compressibility parameters.

11)The reinforcement has a remarkably effect on decreasing the coefficient of volume change and increases the modulus of elasticity which leads to decreasing the settlement

12)The inclusion of the reinforced soil decreasing the coefficient of the permeability which means, that the use of such reinforcement delays the consolidation process.

13)The finite element analysis helped in better understanding of deformation patterns for both reinforced and unreinforced sample. The analysis showed that the reinforcement has a considerable effect on decreasing both the effective stress and the pore water pressure.

\section{References}

1- Abdel-Baki, S. and Raymond, G. P., (1993), “ Soil Reinforcement for Shallow Foundation” Proceeding of $2^{\text {nd }}$ Geotechnical Engineering Conference Cairo, pp. 488-499

2- Abdel-Baki, S. and Raymond, G. P., (1994), “ Improvement of the Bearing Capacity of the Footing by s Single Layer Reinforcement” Proceeding of Geosynthetics Conference Vancouver.

3- Abdrabbo, F. M., (1979), “ Bearing Capacity of a Single Pile Embedded in Reinforced Earth” Alexandria Engineering Journal Vol. 6, pp. 165-175. 
4- Abdrabbo, F. M., and El-Hansy, R. M., (1993), “ Strengthening of Loaded Footing-Soil System” Alexandria Engineering Journal Vol. 32, No. 4, pp. 193-198.

5- Al- Kaisis, A. A. and Abbwai, Z., (2004) “Assessment of Suitability of Some Natural Materials as Soil Reinforcement” Int. Conf. On Geotechnical Engineering, Sharja - UAE, pp. 56-61.

6- Binquet, J., and Lee, K. L., (1975), "Bearing Capacity Tests on Reinforced Slabs” ASCE Journal of Geotechnical Engineering Division, 101, pp. 1241-1255.

7- Bringkgreve, R. B. J and Vermeer, P. A. (1998) "Plaxis Finite Element Code for Soil and Rock Analysis” Version 7 Plaxis B. V., The Netherlands.

8- Giroud, J. P., and Noiray, L., (1981), “ Geotextile-Reinforced Unpaved Road design” ASCE Journal of Geotechnical Engineering Division, 107: 1233-1254.

9- Haripal , P K, Behera, R N and Patra, C R (2008) Behavior of Surface Strip Footing on Geogrid Reinforced Sand Bed. The 12th International Conference of International Association for Computer Methods and Advances in Geomechanics (IACMAG) Goa, India. 3552- 3558

10- Lee, K. L., (1975), “ Laboratory Model Tests on the Application of Composite Fabrics Soft Clay” New Horizons in Construction Materials, Vol.1, Envo Publishing Co. Pennsylvania, pp. 655-682

11- Leshchinsky, D. and Boedeker, R. A., (1989), "Geosynthtic Reinforced Soil Structure” ASCE Journal of Geotechnical Engineering Vol.115, No. 10, pp. 1459-1479

12- Hirao, K.. Yasuhara, K., (1997) “ Geosynthtic Reinforced to Improve Bearing Capacity, Laboratory Testing and Numerical Study” The Fourth International conference on Soil Mech. and Found. Eng. Hamburg Balkema- Rotterdam Vol. 3, pp. 979-994.

13- Mahmoud, M. A., (1988), “ Plate Loading Tests on Reinforced Choesionless Soil” Journal of the Egyptian Society for Soil Mechanics and Foundation Engineering Division, 3.

14- Mandal, J. N., and Manjunath, V. R., (1994), “ Bearing capacity of Strip Footing Resting on Reinforcing Sand Subgrade” Construction and Building Materials, Vol.9, No.1, pp. 35-38.

15- Mofiz, S.A., Taha, M. and Sharker, D. (2004). “ Mechanical and stress strain characteristics and model behavior of geosynthetic reinforced soil composites " $17^{\text {th }}$ ASCE Engineering mechanics Conferences, University of Delaware, pp. 315-322.

16- Patra, C., Das, B. and Atalar, C., (2010), Bearing capacity of embedded strip foundation on geogrid-reinforced sand.Journal of Geotextile and Geomembrane, 23(5), 454-462

17- Saleh, N. M., (2002), "Behavior of Footings Under Centric and Eccentric Loads Adjacent to Reinforced Slopes ” Ain Shams University. Scientific Bulletin Vol., 37, No.4, pp. 41-63.

18- Watn, A. et al., (1997), “ Geosynthtic Reinforced to Improve Bearing Capacity, Laboratory Testing and Numerical Study ” The Fourth International conference on Soil Mech. and Found. Eng. Hamburg Balkema- Rotterdam Vol. 3, pp. 17891796. 